\title{
Manufacturing Technology and Cost Estimation Research on Special Nozzle
}

\author{
Zuo Shilun*
}

School of Mechanical Engineering, Chongqing University of Science \& Technology, Chongqing, 401331, P.R. China

\begin{abstract}
During development process of the static mixer, design and manufacture of the nozzle is key and difficult. In satisfying product quality requirements, try to reduce the manufacturing cost, and shorten development cycle, are main goal of the product developers. This article carried out practical manufacturing technology research though the manufacturing processing design, machining method selection, quality testing, cost analysis of special nozzle, and so on. The results show that the manufacturing process and machining methods are the crucial factors influencing the product manufacturing costs, and reasonably planning manufacturing process, carefully selecting machining method is an important means of reducing manufacturing cost and shorten development cycle.
\end{abstract}

Keywords: Static mixer, nozzle, manufacturing, process, cost.

\section{INTRODUCTION}

Static mixer is a kind of advanced mixer developed in the early 1970s, it is a highly efficient mixing equipment without moving parts, its basic working principle is to use the energy of the flow stream to create mixing between two or more fluids by a series of geometric mixing elements fixed within the mixing chamber [1,2]. Since the 1970s, the static mixer have been applied in the petrochemical, light textile industry and other industries, and achieved good results. But the static mixer as a patent product, the R\&D institutions keep secrecy on its internal structure at home or abroad, mixing chamber is also often made up of disposable sealed structure. Nozzle are key components in the static mixer, the nozzle is a final fluid channel, play the final deceleration, control degree of atomization, exit velocity, jet range, and so forth. Nozzle jet homework is formed directly components, its performance decides the overall performance of the whole injection system, at the same time restricts the other components of the system. Good performance of the nozzle can greatly improve system overall injection performance $[3,4]$. Therefore, solving e design and manufacturing technology of the nozzle, is an important node work for successful research and development of the static mixer.

\section{MANUFACTURING TECHNOLOGY}

\subsection{Manufacturing Process Design}

In view of the special requirements of static mixer structure design, the nozzle structure cannot achieve its rotary center line and the center line of the internal flow channel overlap, where exists a angle of inclination, the size of the angle is decided by its position of assembly on the mixer, and the nozzle internal flow channel must be smooth.

In addition, in order to maintain accurate position during welding and assembling or the nozzle, nozzle profile must be designed into a circular arc surface, the circular arc surface is tangent to inner wall of the mixing chamber, as shown in the Fig. (1).

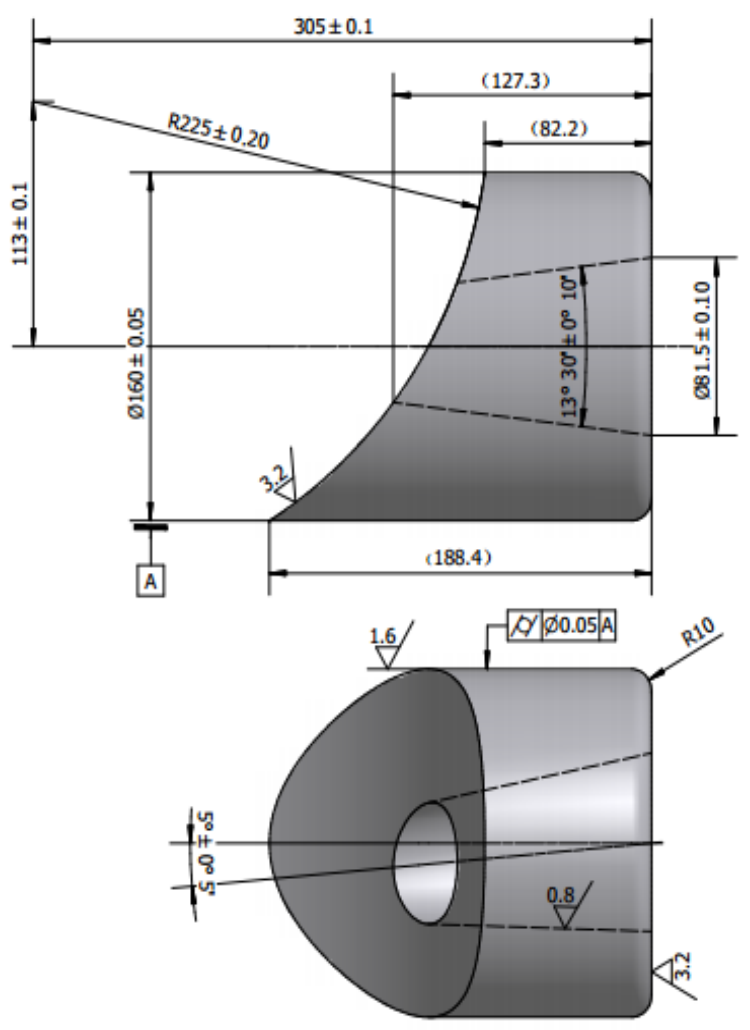

Fig. (1). Nozzle structure. 
So it will greatly increase manufacturing difficulty of the nozzle. Usually turning processing cannot complete the manufacturing of the special t nozzle, while cost is too high by using $3 \mathrm{D}$ printing, consequently the combination manufacturing methods is currently the most common way [5].

Due to its rotary center line do not coincide with the center line of the internal flow channel, so the internal port could not use turning method. Of course, we can carry on wire-cutting in theory, but the latter is extremely high, and the requirement of equipment is difficult to achieve $[5,6]$. At present, we adopt milling. But no matter we use, auxiliary positioning plane must be firstly machined as subsequent positioning installation benchmark. Circular arc surface processing can use milling, also can use wire-cutting processing, only need to consider that is balanceing manufacturing cost with machining efficiency. Therefore, the manufacturing process of the special nozzle is designed as follows:

Procedure 1, blanking.

Procedure 2, turning cylindrical surface and fillet.

Procedure 3, rough machining positioning plane.

Procedure 4, finishing machining positioning plane.

Procedure 5, drilling positioning hole and fixed screw holes.

Procedure 6, rough machining internal flow

Procedure 7, finishing machining internal flow.

Procedure 8, wire-cutting circular arc surface.

According to the process, the shape of parts was changed as shown in Fig. (2).
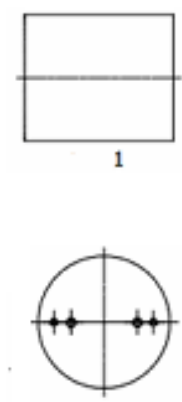

5
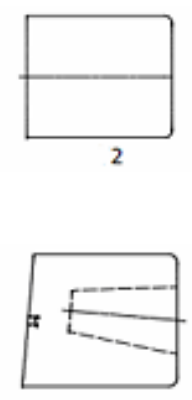

6

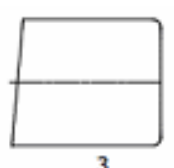

3

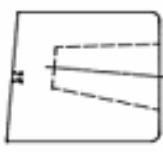

7
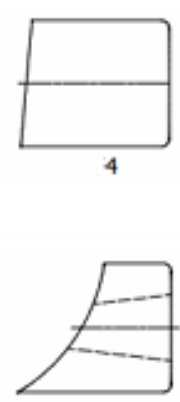

8
Fig. (2). Shape change.

\subsection{Machining Method Selection}

On the premise of machining accuracy, reasonable manufacturing process design and machining method selection are main measures to reduce manufacturing cost.

For larger diameter stainless steel bar, it had better use a chainsaw to blank. Because saw section are more level off, the material loss is also smaller. If use turning, higher requirements for the cutters, material loss is also bigger. Of course, we can also use wire-cutting, but it is too time consuming if using the vertical CNC machine to manufacture the inrenal flow, we must firstly work out positioning installation plane, the plane is a inclined plane, the angle of inclination is same as the inclination angle mentioned in 2.1. The positioning plane can use wire-cutting processing, also can use milling. Using wire-cutting can reduce the dependence on the chucking appliance, but a longer processing time. This paper proposed using wirecutting to finish rough machining, using $\mathrm{CNC}$ milling machine to carry out finishing machining. During the machining process, the location of the normal direction is perpendicular to the machine tool working mesa. The procedure 4,5 and 6 adopt the combined clamp, which is named the three jaw chuck and dividing head together, jaw need to increase the extension of the custom parts clamping rigidity, dividing head used for angle positioning, as shown in Fig. (3).

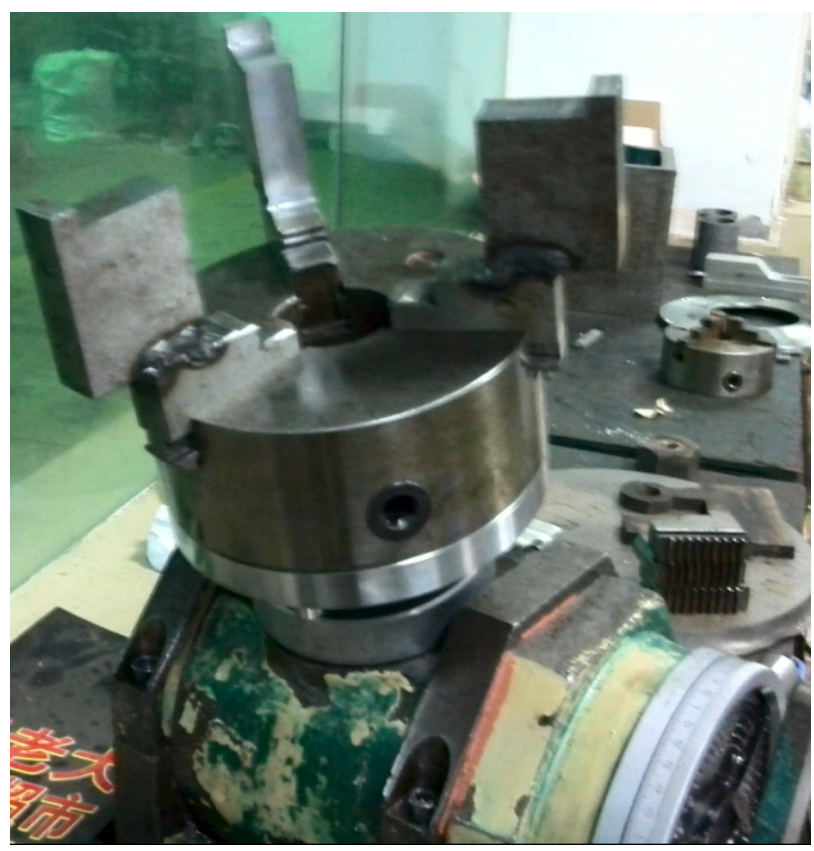

Fig. (3). The combined clamp photos. (4).

The application of the combined clamp is shown in Fig.

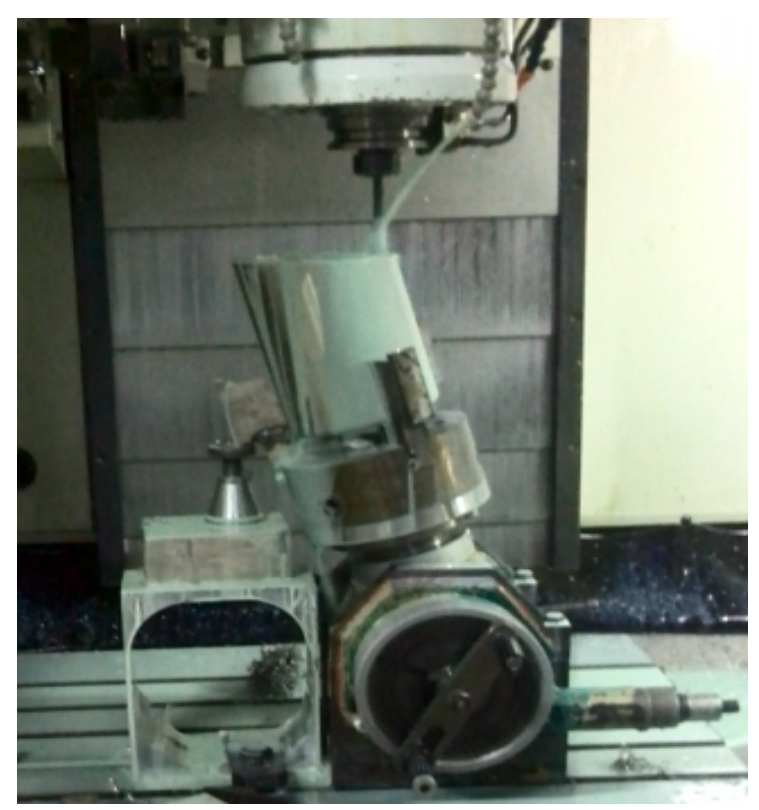

Fig. (4). Scene photos of the procedure 4. 
Internal flow channel milling on the nozzle, the need to use special clamp during the processing, the part should be fixed to the machine tool worktable with press plate, positioning pin and threaded hole, as shown in Fig. (5).

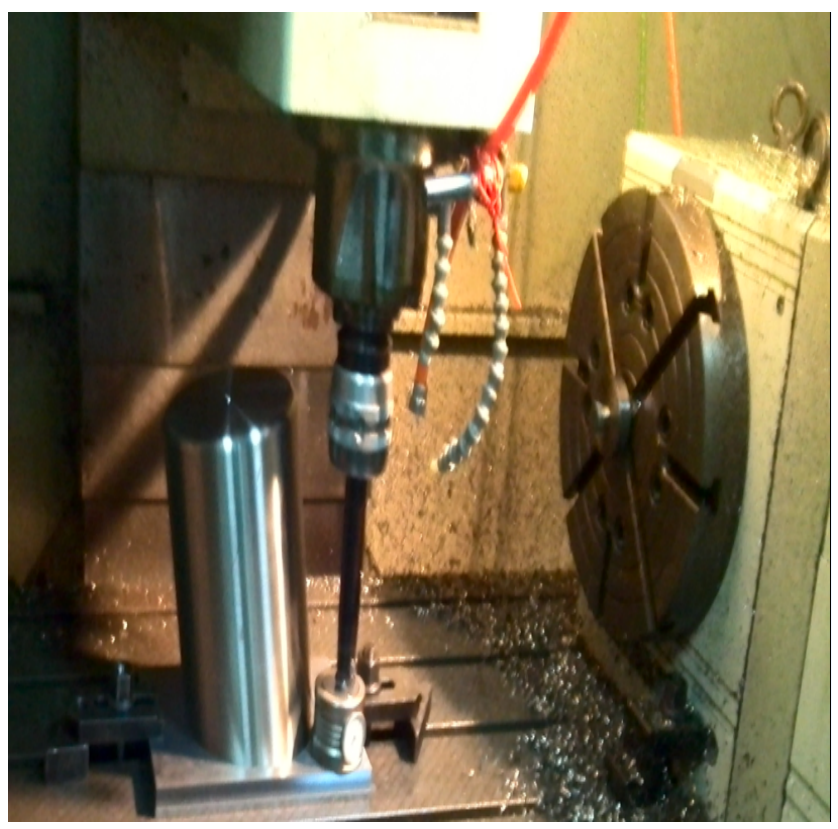

Fig. (5). Adjust cutter photos.

Before cutting the arc surface, a dial indicator can be used to find accurate position of the workpiece firstly [6], and use pressure bar to clamp the part, as shown in Fig. (6).

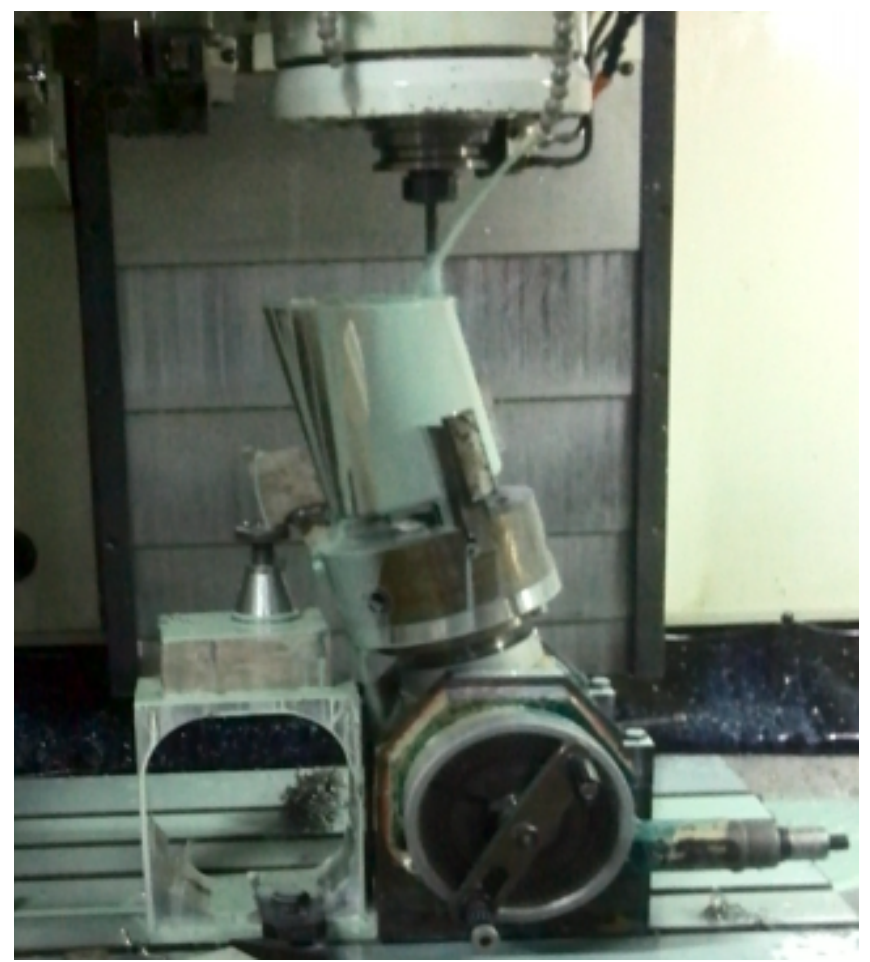

Fig. (6). Adjust workpiece photos.

The machining method and machining time of each procedure was estimated as following Table $\mathbf{1}$.
Table 1. Machining methods and machining time.

\begin{tabular}{|c|c|c|c|}
\hline $\begin{array}{c}\text { Procedure } \\
\text { No. }\end{array}$ & $\begin{array}{c}\text { Processing } \\
\text { Method }\end{array}$ & $\begin{array}{c}\text { Machining } \\
\text { Time (Min) }\end{array}$ & $\begin{array}{c}\text { Non-Cutting } \\
\text { Time (Min) }\end{array}$ \\
\hline \hline 1 & chainsaw & 30 & 15 \\
\hline 2 & numerical control turning & 90 & 60 \\
\hline 3 & wire- cutting & 180 & 30 \\
\hline 4 & CNC milling & 60 & 30 \\
\hline 5 & drilling & 60 & 30 \\
\hline 6 & CNC milling & 210 & 30 \\
\hline 7 & electric spark forming & 420 & 30 \\
\hline 8 & wire-electrode cutting & 210 & 45 \\
\hline
\end{tabular}

\subsection{Manufacturing Quality Testing}

According to design principle of the static mixer, the key factors affecting the quality of nozzle parts are internal flow channel shape and positioning circular arc surface. So we can set the main testing technical indexes, such as inclination angle, surface roughness, arc surface position, and so on, these are technical indicators of the level 1. The nozzle diameter and roughness has certain influence on the welding assembly, this is a secondary technical indicators, other such as rounded corners, nozzle length can be classified as level 3 . For these technical indicators, some available testing tool directly measured, such as nozzle diameter, and some indirect measurement only through other means, such as the port of the taper, more details are shown in the Table 2.

\section{MANUFACTURING COST ESTIMATION}

In general, for a single production, the cost $(C)$ is mainly composed of direct labor $(S)$, equipment handover charge $(M)$, and tooling handover charge $(F)$ (including tool and special clamp cost) [7-10], namely:

$C=S+M+F$

Then, the total manufacturing cost can be expressed by equations, as follows:

$C=\sum_{i=1}^{n} S_{i}+\sum_{i=1}^{n} M_{i}+\sum_{i=1}^{n} F_{i}$

where,

$n$---the number of the procedure, in this study, $n=8$;

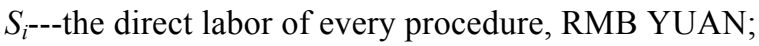

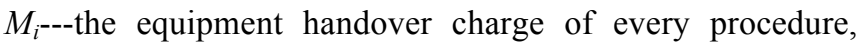
RMB YUAN;

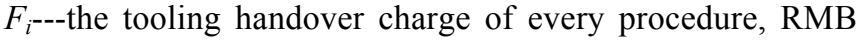
YUAN.

According to the market investigation, facility charge (including energy consumption and depreciation of equipment), and operators hourly wages, are respectively shown in the Table 3. 
Table 2. Quality testing of the nozzle.

\begin{tabular}{|c|c|c|c|c|}
\hline Test Items & Rank & Precision & Method & Tool \\
\hline \hline 1 & Level 2 & $\Phi 160 \pm 0.03$ & Direct measurement & V block + Dial indicator \\
\hline 2 & Level 2 & $\Phi 0.05$ & Indirect measurement & caliper \\
\hline 3 & Level 3 & 188.4 & Direct measurement & \\
\hline 4 & Level 3 & $R 10$ & Visual observation & \\
\hline 5 & Level 3 & $R a 3.2$ & Visual observation & Platform, sine bar, gauge block, micrometer gauge \\
\hline 6 & Level 1 & $5^{0} \pm 5^{\prime}$ & Indirect measurement & Platform, ball, gauge block, micrometer gauge \\
\hline 7 & Level 2 & $13.5^{0} \pm 10^{\prime}$ & Indirect measurement & microscope \\
\hline 8 & Level 1 & $R a 0.8$ & Indirect measurement & \\
\hline
\end{tabular}

Table 3. Equipment use, skilled worker average wage.

\begin{tabular}{|c|c|c|}
\hline Device Name (Type) & $M$ (RMB YUAN/Hour) & $S$ (RMB YUAN/Hour) \\
\hline \hline Band sawing machine (GB42100) & 15 & $15 \sim 25$ \\
\hline Numerical control lathe CK6136 & 35 & $20 \sim 30$ \\
\hline 4 axis milling machining center (VMC-55S) & 100 & $25 \sim 35$ \\
\hline Brisk walking silk wire- cutting machine (DK7740) & 25 & $18 \sim 28$ \\
\hline EDM machine (TH450) & 35 & $20 \sim 30$ \\
\hline
\end{tabular}

The single production requirements for workers technical level is high, so the calculation for ceiling fixture, cutting tools and other auxiliary tooling fee estimate according to actual condition, more details is shown in the Table 4 .

\section{CONCLUSION}

In addition to machining cost, the manufacturing cost of the nozzle should also include the parts material fee (RMB 200YUAN), parts detecting fee (RMB 500YUAN). 20\% of the manufacturing cost as profits of the producer is acceptable due to the single production. It can be seen from the Table 4, the use of equipment and tooling cost accounts for $85 \%$ of the total manufacturing cost, and the use of equipment and tooling is decided directly by the manufacturing process and machining methods. Thus, the manufacturing process and machining method is the decisive factor to affect the product manufacturing costs; to plan reasonably manufacturing process, choose carefully maching method are an important means of reducing manufacturing cost. The nozzle manufacturing cost calculated is RMB 6426.2YUAN, the actual charge of the producer is RMB 6500 YUAN, the two data is very close, it shows that the manufacturing cost estimation method adopted in this paper is effective.

\section{CONFLICT OF INTEREST}

The author confirms that this article content has no conflict of interest.

Table 4. Processing cost estimation.

\begin{tabular}{|c|c|c|c|c|}
\hline Procedure No. & $\boldsymbol{S}$ (RMB YUAN) & $\boldsymbol{M}$ (RMB YUAN) & $\boldsymbol{F}$ (RMB YUAN) & $\boldsymbol{C}$ (RMB YUAN) \\
\hline \hline 1 & 18.8 & 7.5 & 10.0 & 36.3 \\
\hline 2 & 75.0 & 52.5 & 50.0 & 177.5 \\
\hline 3 & 98.0 & 75.0 & 50.0 & 723.0 \\
\hline 4 & 52.5 & 100.0 & 500.0 & 672.5 \\
\hline 5 & 52.5 & 100.0 & 520.0 & 1090.0 \\
\hline 6 & 140.0 & 350.0 & 1000.0 & 1470.0 \\
\hline 7 & 225.0 & 245.0 & 50.0 & 350.0 \\
\hline Total (RMB YUAN) & 127.5 & 222.5 & 1152.5 & 4771.8 \\
\hline
\end{tabular}




\section{ACKNOWLEDGEMENTS}

Declared none.

\section{REFERENCES}

[1] M. Mutsaki, F.A. Streiff and G. Schneider, "Advances in static mixing technology", Chem. Eng. Prog, vol. 82, pp. 42-48, 1986.

[2] A. Bakker and R. LaRoche, "Flow and mixing with Kenics static mixer", Cray Channels, vol. 15, pp. 25-28, 1993.

[3] J. Yuying, G. Liehang, X. Xinlin, J. Runlian, and W. Ke, "Comparison of property parameters of pre-mixed abrasive water jet nozzles by simulation approach", JDCTA, vol. 7, no. 5, pp. 935942, 2013

[4] D. Kandhai, D.J.E. Vidal, A.G. Hoekstra, H. Hoefsloot, P. Iedema, and P.M.A. Sloot, "Lattice-Boltzmann and finite element simulations of fluid flow in a Smrx static mixer reactor", Int. J. Numer. Meth. Fluids, vol. 31 pp. 1019-1033, 1999.
[5] Z. Shilun, "Products development based on the technology of design for manufacturing and assembly", Int. J. Adv. Comput. Technol., vol. 6, no. 3, pp. 132-141, 2014.

[6] Z. Shilun, and W. Jiaxu, "Comprehensive welding technology for type 304 stainless steel rotating shaft", AISS, vol. 4, no. 11, pp. 210- 216, 2012.

[7] Y.T. Tsai, and Y. M. Chang, "Function-based cost estimation integrating quality function deployment to support system design", Int. J. Adv. Manuf. Tech., vol. 23, no. 7-8, pp. 514-522, 2004.

[8] A. Fiorentino, "Cost drivers-based method for machining and assembly cost estimations in mould manufacturing", Int. J. Adv. Manuf. Tech., vol. 70, no. 5-8, pp. 1437-1444, 2014

[9] P. Duverlie, and J. M. Castelain, "Cost estimation during design step: parametric method versus case based reasoning method", Int. J. Adv. Manuf. Tech., vol. 15, no. 12, pp. 895-906, 1999.

[10] L. Kai-Shi, H. Wen-Quan and Z. Rong-Gang, "A study of pipe cost-estimation based on analogous method", J. Sichuan Univ. (Nat. Sci. Ed), no. 6, pp. 78-81, 2008. 